\title{
Chemo-enzymatic production of omega-3 monoacylglycerides using sponge-like ionic liquids and supercritical carbon dioxide
}

Received 00th January 20xx, Accepted 00th January 20xx DOI: $10.1039 / x 0 x \times 00000 x$

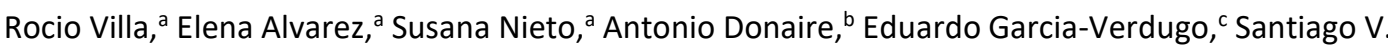 \\ Luis, ${ }^{\mathrm{C}}$ and Pedro Lozano*a
}

\begin{abstract}
A clean chemo-enzymatic synthesis of omega-3 monoacylglycerides was carried out by two consecutive catalytic steps, the enzymatic transesterification of raw fish or linseed oil with solketal for producing fatty acid solketyl esters, followed by the hydrolysis of these solketal moieties catalysed by solid acids (e.g. zeolites) in either supercritical carbon dioxide $\left(\mathrm{scCO}_{2}\right)$ or sponge-like ionic liquids (SLILs). By using $\mathrm{scCO}_{2}$ as reaction/extraction medium, an excellent performance of both coupled catalytic steps was observed when t-butanol was used as a co-solvent, resulting in a 100\% monoacylglyceride yield for seven days under continuous operation and without any loss in catalytic activity. For discontunuous operation, the process involved two separated steps in SLIL and water, respectively, leading to $100 \%$ product yield and IL-free monoacylglyceride product by following a cooling and centrifugation protocol, which allow for the full recovery of the enzyme / SLIL / zeolite components of the reaction system that could be reused for at least 6 cycles with unchanged catalytic performance.
\end{abstract}

\section{Introduction}

Polyunsaturated fatty acids (PUFAs), like $\alpha$-linolenic acid (ALA), eicosapentaenoic acid (EPA) and docosahexaenoic acid (DHA) are essential bioactive molecules in human nutrition with recognized beneficial health effects (e.g. as cardioprotective agents) and disease prevention (e.g. anti-inflammatory effects by interfering with the production of leukotrienes, interleukin-1 and tumor necrosis factor). ${ }^{1}$ However, the bioavailability of PUFAs after their consumption as dietary triacylglycerides is limited affected under maldigestion and malabsorption conditions (e.g. chronic pancreatitis, Crohn's disease, cystic fibrosis, Shwachman-Diamond syndrome, post-surgery effects, etc.). ${ }^{2}$ Thus, current strategies to combat lipid malabsorption include dietary supplements containing monoacylglycerides (MAGs) based on polyunsaturated fatty acids (see Fig. $1 \mathrm{~A}$ ), because they are better absorbed than those delivered as triacylglycerides. ${ }^{1,3}$ Furthermore, among the different types of lipid derivatives containing omega- 3 fatty acids, MAGs have shown the best stability against oxidation. ${ }^{4}$ Besides, the synthesis of MAGs is also of great industrial interest because they are very useful nonionic emulsifiers for food and cosmetic industries products, as well as, as bioactive compounds of interest in medicinal chemistry (e.g. as

\footnotetext{
Departamento de Bioquímica y Biología Molecular B e Inmunología. Facultad de Química, Campus Regional de Excelencia Internacional "Mare Nostrum". Universitdad de Murcia, Campus de Espinardo. E-30100. Murcia. Spain.

b. Departamento de Química Inorgánica. Facultad de Química, Campus Regional de Excelencia Internacional "Mare Nostrum". Universidad de Murcia, Campus de Espinardo. E-30100. Murcia. Spain.

c. Departamento de Química Inorganica y Organica. Universidad Jaume I. Campus del Riu Sec, E-12071, Castellon, Spain.

† Footnotes relating to the title and/or authors should appear here.

Electronic Supplementary Information (ESI) available: [details of any supplementary information available should be included here]. See DOI: 10.1039/x0xx00000x
}

antimicrobial, for prevention prostatic hyperplasia, as drug carriers, etc.). ${ }^{5}$

Commercial MAGs are usually produced by chemical glycerolysis of fats/oils with glycerol at high temperatures (220-250 으) in a nitrogen atmosphere, using inorganic alkaline catalysts. ${ }^{6}$ The use of high temperature has some drawbacks as a result of uncontrolled side reactions (e.g. dark colour, burnt taste, oxidation, etc.), as well as those associated to high energy consumption. Furthermore, this chemical glycerolysis usually provides $35-60 \%$ MAGs, $35-50 \%$ diacylglycerides (DAGs), 1-20\% triacylglycerides (TAGs) and 1-10\% free fatty acids (FFAs) along the corresponding alkali metal salts. Thus, MAGs need to be isolated from the reaction mixture by molecular distillation, ${ }^{7}$ to achieve at least $70 \%$ purity, as requested by the World Health Organization and the EU directives. ${ }^{8}$

The lipase-catalysed glycerolysis of fish (e.g. sardine, anchovy, tuna, etc.) or vegetable (e.g. linseed, etc.) oils is a classical approach for the production of omega-3 MAGs, because of the high selectivity of enzyme-catalysed reactions and the required mild conditions that avoid undesired side-reactions. However, the mutual non-miscibility of TAGs and glycerol leads to the formation of biphasic systems with low efficiency for the biocatalytic synthesis of MAGs. ${ }^{9}$ Several strategies based on reaction medium engineering, such as the use of organic cosolvents (e.g. $t$-pentanol, $t$-butanol, etc.), ${ }^{9 b, 10}$ emulsification approaches, ${ }^{4 a, 11}$ or the previous adsorption of glycerol onto solid carriers like silica gel, ${ }^{12}$ have been assayed in order to provide efficient monophasic reaction media. Through these approaches, TAGs conversions reached up to $90 \%$, although with selectivity that provided the desired MAGs in up to $80 \%$ yield (e.g. the Novozym 435-catalysed sardine oil glycerolysis in 50\% w/w $t$ pentanol resulted in around $80 \%$ MAGs, after $3 \mathrm{~h}$ of reaction at $\left.50^{\circ} \mathrm{C}\right) .{ }^{9 b}$ Nevertheless, it should be noted that all additives included into the reaction media to improve MAGs yield should be removed 
A

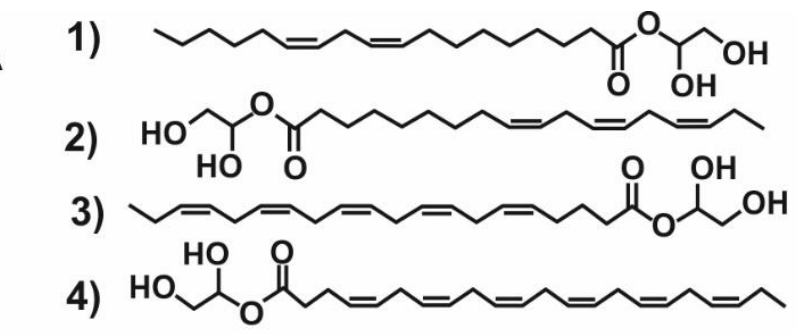

B

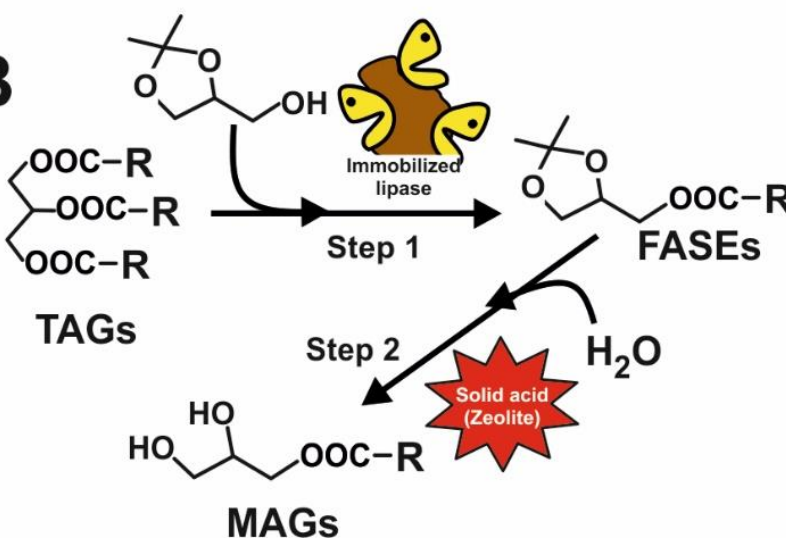

Figure 1. A. Polyunsaturated fatty acids: 1), linoleic acid; 2) alpha-linolenic acid; 3) eicosapentaenoic acid; 4) docosahexaenoic acid. B. Two-step chemo-enzymatic synthesis of MAGs. Step 1: Lipase-catalysed transesterification of TAGs with solketal under anhydrous conditions; Step 2: Solid acid-catalysed the selective hydrolysis of solketyl moiety under aqueous conditions.

before their further use as nutraceutical. Similar results were obtained for the synthesis of MAGs rich in omega-3 PUFAs when using supercritical carbon dioxide $\left(\mathrm{scCO}_{2}, 150-250\right.$ bar, $\left.50{ }^{\circ} \mathrm{C}\right)$, as a green reaction medium to assist the enzymatic glycerolysis of sardine oil. ${ }^{4 a}$ As an alternative approach, the production of 2-MAGs by the sn-1,3 regiospecific lipase-catalysed ethanolysis of TAGs was also assayed, although the mutual non-miscibility between ethanol and TAGs once again provided a low efficient biphasic system. ${ }^{13}$ As an example of this approach, the time-course profile of Lipozyme435catalysed ethanolysis of tune oil (ethanol:oil 3:1 w/w) led to a continuous increase in ethyl ester products, while the 2-MAGs profile showed a bell-shaped curve having a $27 \%$ maximum yield at $2 \mathrm{~h}$ of reaction and then decreasing. By stopping the reaction at this time, 2-MAGs were separated by using volatile organic solvents (e.g. hexane) and then recovered by low temperature solvent crystallization and molecular distillation. ${ }^{13 c}$ Alternatively, $\mathrm{scCO}_{2}(100-$ 300 bar, $50-70{ }^{\circ} \mathrm{C}$ ) has also been used as solvent for the Lipozyme435-catalysed ethanolysis of fish oil rich in omega-3 PUFAs, resulting in a bell-shape time-course profile for MAGs with up to 12 $15 \%$ yield after 90 min of reaction. The subsequent fractionation of reaction products by supercritical fluid extraction (SFE, 100-280 bar, $25-60{ }^{\circ} \mathrm{C}$ ) yielded an extract rich in fatty acid ethyl esters (FAEE) (up to $99.46 \%$ wt.), and a MAGs raffinate with up to $82.25 \%$ wt. $^{14}$

From the beginning of this century, ionic liquids (ILs) were pointed out as exceptional non-aqueous reaction media for carrying out both chemocatalytic, ${ }^{15}$ and biocatalytic processes. ${ }^{16}$ Because of their unique array of physical-chemical properties (e.g. low vapor pressure, non-flammability, high ionic conductivity, solvent power, high thermal and chemical stabilities, etc.), ${ }^{17}$ ILs have been shown as an exceptional enabling tool to integrate reaction and separation processes. ${ }^{18}$ Furthermore, when using ILs as supported phases (e.g. supported ionic liquid like phases, SILLPs) they provide an excellent microenvironment for (bio)catalysts leading to develop efficient chemo-enzymatic processes under supercritical conditions. ${ }^{19}$ With respect to the synthesis of MAGs, it was reported that the glycerolysis of sunflower oil led to $69 \%$ yield when using alkaline ILS (e.g. 1-butyl-3-methylimidazolium imidazolate [Bmim][Im]) at $200{ }^{\circ} \mathrm{C},{ }^{20}$ or up to $90 \%$ yield for the case of a lipase immobilized in the amphiphilic cocosalkylpentaethoximethylammonium methanosulfate IL at $600^{\circ} \mathrm{C}^{21}$ In both cases, strategies for the recovery of the MAGs product, and the reuse of the IL involved the use of organic solvents (e.g. toluene).

The discovery of the sponge-like character of ILs (the so called Sponge-Like Ionic Liquids, SLILs), based on cations with long alkyl side-chains, (e.g. 1-octadecyl-3-methylimidazolium bis(trifluoromethylsulfonyl)imide, $\left.\left[\mathrm{C}_{18} \mathrm{mim}\right]\left[\mathrm{NTf} \mathrm{f}_{2}\right]\right)$, has opened new opportunities for developing clean biocatalytic processes. ${ }^{22}$ As temperature-switchable liquid/solid phases, these SLILs have successfully been used for producing nearly pure synthetic compounds of high added value (e.g. flavour esters, biodiesel, etc.) in two steps: a biocatalytic step that occurs in monophasic liquid systems, followed by a product separation step carried out by cooling/centrifugation/filtration of the solid reaction system. ${ }^{18,23}$ In this context, the biocatalytic synthesis of monoacylglycerides (MAGs) was reported by the direct esterification of fatty acids (e.g. lauric, palmitic, oleic, etc.) with glycerol in different SLILs, obtaining up to $100 \%$ selectivity and 100\% MAG yield. However, while monoolein was easily separated from the SLIL with water, it was necessary the use dodecane for separating monolaurin. ${ }^{24}$

Solketal (1,2-isopropylideneglycerol) is a glycerol derivative obtained by an acid-catalysed ketalization under anhydrous conditions. This ketal has been reported as an useful nucleophile for the biocatalytic synthesis of oxygenated biofuels (fatty acid solketyl esters, FASEs) by transesterification of vegetable oils in SLILs (e.g. near to $100 \%$ yield in $6 \mathrm{~h}$ at $\left.60{ }^{\circ} \mathrm{C}\right) .{ }^{25}$ Furthermore, it was also reported how solketal can be hydrolysed in aqueous medium by acidcatalysts, providing glycerol and acetone. ${ }^{26}$

In this context, this paper shows by the first time a straightforward and clean protocol for producing nearly pure omega-3 MAGs, based on a chemo-enzymatic process assisted by $\mathrm{scCO}_{2}$ or SLILs technologies under continuous or discontinuous operation, respectively. Thus, the enzymatic transesterification of linseed and fish oils containing omega-3 TAGs with solketal in SLILs was firstly carried out under anhydrous conditions, then the solketyl moiety of the obtained FASEs being then selectively hydrolysed by solid acids (e.g. zeolites) under aqueous conditions (see Fig. 1B). The excellent suitability of the proposed approach was demonstrated as a function of both the yield and purity of the obtained omega-3 MAGs, as well as by the recovery and further reuse of all the elements of the reaction system (biocatalyst, acid catalyst, SLIL, etc.). 


\section{Experimental}

\section{Materials}

Immobilized Candida antarctica Lipase B (Novozym 435, EC 3.1.1.3) was from Novozymes S.A. (Spain). Crude fish oil from menhaden, linseed oil, solketal (99\% purity), molecular sieves (MSX13; $270 \mathrm{mg}$ $\mathrm{H}_{2} \mathrm{O} / \mathrm{g}$ adsorption capacity), solvents and other chemicals were supplied from Sigma-Aldrich-Fluka (Madrid, Spain). Octadecyltrimethylammonium bis(trifluoromethylsulfonyl)imide ( $\left.\left[\mathrm{C}_{18} \mathrm{tma}\right]\left[\mathrm{NTf}_{2}\right]\right), 99 \%$ purity; $\mathrm{mp} 74{ }^{\circ} \mathrm{C}$ was obtained from loLiTec $\mathrm{GmbH}$ (Germany). Zeolite H-Beta CP811E-150 $\left(\mathrm{SiO}_{2}: \mathrm{Al}_{2} \mathrm{O}_{3}\right.$ ratio=300), zeolites $\mathrm{H}-\mathrm{Y}$ CBV720 ( $\mathrm{SiO}_{2}: \mathrm{Al}_{2} \mathrm{O}_{3}$ ratio=30), and $\mathrm{HY}$ CBV 400 $\left(\mathrm{SiO}_{2}: \mathrm{Al}_{2} \mathrm{O}_{3}\right.$ ratio=5.1), were obtained from Zeolysts International (PA, USA).

\section{Novozym 435-catalysed FASEs synthesis in [ $\mathrm{C}_{18} \mathrm{tma}^{\mathrm{tm}}\left[\mathrm{NTf}_{2}\right]$}

Into a $5 \mathrm{~mL}$ test tube with a vacuum septum, $1 \mathrm{mmol}$ of fish or linseed oil, were mixed with $3.5 \mathrm{mmol}$ of solketal, and the corresponding amount of the IL to reach $40 \%(\mathrm{w} / \mathrm{w})$ final concentration with respect to the overall mass. The resulting reaction mixture was preincubated at $60 \stackrel{\circ}{\circ}$ for 10 minutes, leading to a monophasic system after the IL melting, and then $150 \mathrm{mg}$ of molecular sieves MSX13 were also added. Finally, the reaction was started by adding $100 \mathrm{mg}$ of Novozym 435, the mixture being shaken ( $300 \mathrm{rpm}$ ) under vacuum conditions for $6 \mathrm{~h}$ at $60{ }^{\circ} \mathrm{C}$. To obtain time-course profiles, $20 \mu \mathrm{L}$ aliquots were taken at regular intervals and suspended in $480 \mu \mathrm{L}$ of octane/isopropanol $(95: 5, \mathrm{v} / \mathrm{v})$ solution. The resulting solutions were strongly shaken for 3 minutes, and then centrifuged at 15,000 rpm for 15 minutes at $5{ }^{\circ} \mathrm{C}$ to precipitate the solid SLIL. The upper solution was analysed by GC.

\section{Zeolite-catalysed solketal hydrolysis}

The acid zeolite-catalysed selective hydrolysis of ketal ring of solketa in presence of an ester compound was tested, as follows: Into a $5 \mathrm{~mL}$ test tube with a vacuum septum, solketal $(0.5 \mathrm{mmol})$, ethyl decanoate $(0.5 \mathrm{mmol})$ and water $(3 \mathrm{mmol})$ were dissolved in $t$ butanol (1-mL final volume), and the resulting reaction mixture was pre-incubated at the selected temperature for 10 minutes. The reaction was started by adding $150 \mathrm{mg}$ of acid zeolite (CBV400, CBV720 or CP811-C) under shaking (300 rpm) and controlled temperature. At different reaction times, samples $(20 \mu \mathrm{L})$ were taken and dissolved in $480 \mathrm{~mL}$ of $t$-butanol, then analysed by GC.

\section{Coating of Novozym 435 particles with $\left.\left[\mathrm{C}_{18} \mathrm{tma}\right] \mathrm{NTf}_{2}\right]$}

In a 10-mL capacity test tube, $0.5 \mathrm{~g}$ of $\left[\mathrm{C}_{18} \mathrm{tma}\right]\left[\mathrm{NTf}_{2}\right] \mathrm{IL}$ were dissolved in $5 \mathrm{~mL}$ of acetonitrile. Then, $2.5 \mathrm{~g}$ of Novozym 435 were added, and the mixture was gently stirred for $30 \mathrm{~min}$ at room temperature. Finally, the solvent was eliminated by continuous bubbling of $\mathrm{N}_{2}$ for $30 \mathrm{~min}$ at room temperature, and the resulting biocatalyst-IL particles were ready for their use.

\section{Continuous chemocatalytic synthesis of omega-3 MAGs in $\mathrm{scCO}_{2}$}

Both catalyst, the biocatalyst-IL ( $3 \mathrm{~g})$ and the zeolite $(3 \mathrm{~g})$ were respectively packed into two different stainless steel tubular reactors (10 $\mathrm{mL}$ capacity), being then connected by $1 / 16^{\prime \prime}$ tubing and placed inside two different heater systems at controlled temperature. As depicted in Fig. 4, the enzymatic reactor was continuously feed by triglycerides (i.e. fish oil or linseed oil) $(76 \mu \mathrm{L} / \mathrm{min} ; 8 \mu \mathrm{mol} / \mathrm{min})$ and solketal ( $36 \mu \mathrm{L} / \mathrm{min} ; 28.8 \mu \mathrm{mol} / \mathrm{min}$ ) by using two different HPLC pumps, while the $\mathrm{scCO}_{2}$ flow $(1.5 \mathrm{~mL} / \mathrm{min}, 180$ bar) was provided by a supercritical pump (Model PU-2080 $\mathrm{CO}_{2}$, Jasco). At the exit of the enzymatic reactor, the reaction mixture flow was continuously mixed with a $1: 1(\mathrm{v} / \mathrm{v})$ water:t-butanol solution $(10 \mu \mathrm{L} / \mathrm{min} ; 278 \mu \mathrm{mol}$ $\mathrm{H}_{2} \mathrm{O} / \mathrm{min}$ ) by using a HPLC pump, and introduced to the catalytic reactor containing acid zeolite catalyst. The system was finally equipped by an automatic backpressure regulator (Model BP 2080, Jasco) able to continuously deliver the reaction products at room conditions by bubbling in a controlled amount of $t$-butanol placed on an ice-bath for $30 \mathrm{~min}$ intervals. Samples $(20 \mu \mathrm{L})$ were dissolved in $480 \mu \mathrm{L}$ of $t$-butanol, then analysed by GC. In all cases, substrate and product mass-balances from the outlet were consistent with the substrate mass-flow inlet.

\section{Chemocatalytic synthesis of omega-3 MAGs in liquid medium.}

The synthesis of omega-3 MAGs was carried out by following two consecutive catalytic steps. The first step consisted in the enzymatic transformation of the omega-3 triglycerides to produce omega-3 FASEs in $\left[\mathrm{C}_{18} \mathrm{tma}\right]\left[\mathrm{NTf}_{2}\right]$, as described above. At the end of this biocatalytic step, the immobilized enzyme was separated by centrifugation, washed with $0.2 \mathrm{~mL}$ of $t$-butanol, and stored for further reuse. On the other side, the liquid reaction medium was collected into a 2-mL centrifugal vial, mixed with hot water $(0.7 \mathrm{~mL}$,

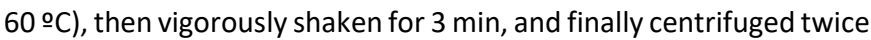
(15 $000 \mathrm{rpm}, 15$ minutes, $15^{\circ} \mathrm{C} ; 15000 \mathrm{rpm}, 15 \mathrm{~min}, 5^{\circ} \mathrm{C}$ ), resulting in a three-phase system. The upper phase contains the free- IL omega-3 FASEs, the middle aqueous phase contains the unreacted solketal, whereas the IL (solid phase) was at the bottom of the vial, as a result of the sponge-like behaviour of the IL.22,23 The upper phase product was carefully collected, and used for the next catalytic step. For the determination of the residual IL content in this upper phase product, an aliquot of $15 \mu \mathrm{L}$ of the top liquid phase was dissolved in $0.485 \mu \mathrm{L}$ of acetone- $\delta_{6}$ containing $5 \mu \mathrm{L}$ of TFA (internal standard), then analysed by $282 \mathrm{MHz}{ }^{19} \mathrm{~F}$ NMR in Bruker AC $300 \mathrm{E}$ spectrometer (see ESI). The second catalytic step consisted in the hydrolytic opening of the solketyl-ring moiety in omega-3 FASEs to produce omega-3 MAGs in water medium. Into a $1.5 \mathrm{~mL}$ vial, $250 \mu \mathrm{L}$ (0.6 mmol) of omega-3 FASEs were mixed with $81 \mu \mathrm{L}(4.5 \mathrm{mmol})$ of

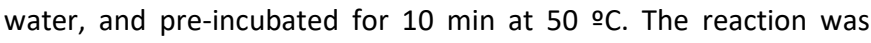
started by adding the CBV720 acid zeolite $(40 \mathrm{mg})$, and the resulting mixture was maintained under shaking for $3 \mathrm{~h}$ at $50{ }^{\circ} \mathrm{C}$. To obtain time-course profiles, $15 \mu \mathrm{L}$ aliquots were taken and suspended in 485 $\mu \mathrm{L}$ of $t$-butanol:isopropanol (1:1 v:v), and the resulting mixture was shaken and centrifuged ( $5 \mathrm{~min}, 15.000 \mathrm{rpm}, \mathrm{RT}$ ) to separate the solid zeolite, then the liquid phase was analysed by GC. For zeolite recovery and reuse experiments, the catalyst was separated by centrifugation of the reaction mixture, collected, and washed with $t$ butanol for several times, and finally oven dried for $8 \mathrm{~h}$ at $70^{\circ} \mathrm{C}$.

\section{Gas Chromatography Analysis.}

GC analysis was performed with a GC-2010-Plus apparatus (Shimadzu Europe, Germany) equipped with a flame ionization detector (FID). Fatty Acid Solketal Esters samples were analysed on a TRB-BIODIESEL column $(10 \mathrm{~m} \times 0.32 \mathrm{~mm} \times 0.1 \mu \mathrm{m}$, Teknokroma, Spain) under the following conditions: carrier gas (He) at 129.9 $\mathrm{mL} / \mathrm{min}$; split ratio $80: 1$; temperature program: $170{ }^{\circ} \mathrm{C}, 2 \mathrm{~min}$; 
$3{ }^{\circ} \mathrm{C} / \mathrm{min}, 230^{\circ} \mathrm{C} ; 15^{\circ} \mathrm{C} / \mathrm{min}, 350^{\circ} \mathrm{C}, 5 \mathrm{~min}$. Peak retention times (min) were as follows: Palmitic acid solketyl ester, 22.1; Polyunsaturated C-18 acid solketyl esters, 23.8, Stearic acid solketyl ester, 24.0; Eicosapentaenoic acid solketyl ester, 25.1; Docosahexaenoic acid solketyl ester, 26.4. For GC analysis of monoacylglycerides, a TRB-1 column $(30 \times 0.15 \mathrm{~mm} \times 0.53 \mu \mathrm{m}$, Teknokroma, Spain) was used under the following conditions: carrier gas $(\mathrm{He})$ at $129.9 \mathrm{~mL} / \mathrm{min}$; split ratio $80: 1$; temperature program: $50{ }^{\circ} \mathrm{C}, 2 \mathrm{~min} ; 10^{\circ} \mathrm{C} / \mathrm{min} ; 350^{\circ} \mathrm{C}, 7 \mathrm{~min}$. Peak retention times (min) were as follows: glyceryl palmitate, 22.4; glyceryl polyunsaturated C18 acids, 26.5 and 26.6; glyceryl eicosapentaenate, 32.1; glyceryl docosahexaenate, 33.9.

Identification of monoglycerides by GC-MS. GC-MS analyses were carried out by using a GC-6890 apparatus (Agilent, USA) coupled to a MS-5973 (Agilent, USA) system. The GC was equipped with a HP-5MS column ( $30 \times 0.25 \mu \mathrm{m} \times 0.25 \mu \mathrm{m}$, Agilent, USA) used under the following conditions: carrier gas (He) at $103 \mathrm{~mL} / \mathrm{min}$; inlet split ratio: 100:1; temperature program: $8{ }^{\circ} \mathrm{C} / \mathrm{min}, 150{ }^{\circ} \mathrm{C}, 5 \mathrm{~min} ; 3^{\circ} \mathrm{C} / \mathrm{min}$, $280^{\circ} \mathrm{C}, 2 \mathrm{~min}$; MS source ionization energy $70 \mathrm{eV}$. The scan time was $0.5 \mathrm{~s}$, covering a mass range $400-800$ amu mass range. Glyceryl palmitate, retention time $(\mathrm{rt}, \mathrm{min}): 38.4$, positive ion $(\mathrm{m} / \mathrm{z}): 43.1$, 71.1, 101.1, 129.1, 149.1, 171.1, 191.2, 213.2, 239.3, 269.1, 312.3 334.3. Glyceryl monooleate, Glyceryl monolinoleate, Glyceryl monolinolenate, rt: 44.2 , positive ion (m/z): 55.0, 79.1, 108.2, 135.2, 173.2, 204.2, 232.3, 264.3, 296.1, 321.3, 352.3. Glyceryl eicosapentaenate, rt: 46.4 , positive ion $(\mathrm{m} / \mathrm{z})$ : $55.1,79.1,117.1$, 147.1, 171.1, 207.1, 249.1, 281.1, 313.3, 339.3. Glyceryl docosahexaenate, $\mathrm{rt}: 52.8$, positive ion $(\mathrm{m} / \mathrm{z}): 55.1,81.7,117.1,145.2$, 207.1, 231.2, 255.2, 281.1, 301.3, 327.1, 353.3, 386.4.

\section{Results and discussion}

In an attempt to develop simple and sustainable protocols for the production of omega-3 monoacylglycerides from natural resources (fish or linseed oil), the reported synergic advantages resulting from the combination of immobilized enzymes with SLILs/scCO $\mathrm{CO}_{2}$ have been tested. ${ }^{18}$ By this technology, integrated processes for (bio)catalytic transformations and pure product separation can be easily designed either in continuous or in discontinuous approaches with full recovery of the catalytic systems (catalysts, IL, etc.) for further reuse. ${ }^{19,22}$ The proposed (bio)catalytic approach for the synthesis of omega-3 MAGs (see Fig. 1) involves two key steps. The synthesis of FASEs by Novozym 435-catalyses transesterification reaction of omega-3 triglycerides using solketal as the nucleophile in a SLIL was firstly tested. Then, the suitability of the acid zeolite-catalyses selective hydrolysis of the ketal ring with preservation of the ester linkage in aqueous medium was studied. Both catalytic steps were incorporated in a continuous or discontinuous process, properly designed to directly provide the omega-3 MAGs products. For the case of the continuous process, the reaction system was operated under a $\mathrm{scCO}_{2}$ flow for mass transport through the consecutively connected catalytic reactors.

\section{Lipase-catalysed FASEs synthesis in the $\left[\mathrm{C}_{18}\right.$ tma] $\left[\mathrm{NTf}_{2}\right] \mathrm{IL}$.}

The suitability of immobilized Candida antarctica lipase B to carry out the biocatalytic synthesis of omega-3 FASEs was first studied by a transesterification approach in the $\left[\mathrm{C}_{18} \mathrm{tma}^{\mathrm{m}}\left[\mathrm{NTf}_{2}\right] \mathrm{IL}\right.$ as reaction medium at $60^{\circ} \mathrm{C}$. Two different omega-3 enriched oils (i.e.,

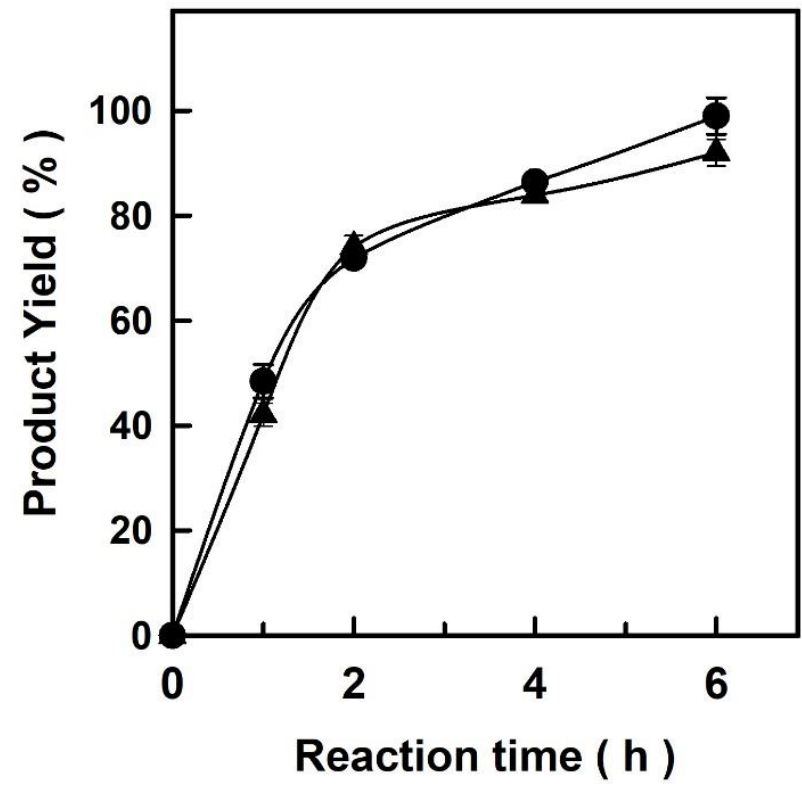

Figure 2. Yields obtained for the Novozym-435-catalysed synthesis of FASEs by the transesterification of triacylglycerides from linseed $(\mathbf{O})$ or fish oil $(\mathbf{\Delta})$ with solketal in $40 \% \mathrm{w} / \mathrm{w}\left[\mathrm{C}_{18} \mathrm{tma}\right]\left[\mathrm{NTf}_{2}\right]$ at $60^{\circ} \mathrm{C}$.

menhaden crude fish and linseed oils) were tested as acyl donors, while solketal was the nucleophile acceptor for both cases. As a representative example, Fig. 2 depicts the time course for the Novozym 435-catalysed omega-3 FASEs synthesis by

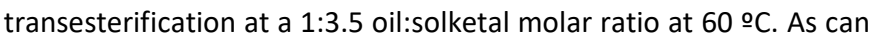
be seen, the biocatalytic system was able to produce up to $99 \%$ FASEs yield in $6 \mathrm{~h}$ from these enriched omega-3 oils, a profile similar to the one previously reported for cottonseed oil. ${ }^{25}$ This excellent suitability of immobilized lipases to carry out the transesterification reaction on oils can be related to the ability of the hydrophobic ionic liquids based on cations with long alkyl side chains, like $\left.\left[\mathrm{C}_{18} \mathrm{tma}\right] \mathrm{NTf}_{2}\right]$, to simultaneously dissolve both the omega-3 oil and the alcohols, resulting monophasic reaction media, enhancing transport rate of substrates/products towards and from the enzyme microenvironment, which was independent of the nature of the oil source.22 Furthermore, it was observed how the assayed omega-3 oil:solketal molar ratio was an important parameter to achieve the

Table 1. Influence of the linseed oil:solketal molar ratio on the Novozym435-catalysed FASEs synthesis in $40 \%(\mathrm{v} / \mathrm{v})\left[\mathrm{C}_{18} \mathrm{tma}\left[\mathrm{NTf} \mathrm{F}_{2}\right] \mathrm{IL}\right.$ at $60^{\circ} \mathrm{C}$.

\begin{tabular}{ccc}
\hline Entry & $\begin{array}{c}\text { Linseed oil :solketal ratio } \\
\text { ratio (mol/mol) }\end{array}$ & $\begin{array}{c}\text { FASEs Yield } \\
(\%)\end{array}$ \\
\hline 1 & $1: 2$ & 66.9 \\
2 & $1: 2.5$ & 73.0 \\
3 & $1: 3$ & 92.2 \\
4 & $1: 3.5$ & 99.0 \\
5 & $1: 6$ & 100 \\
\hline
\end{tabular}




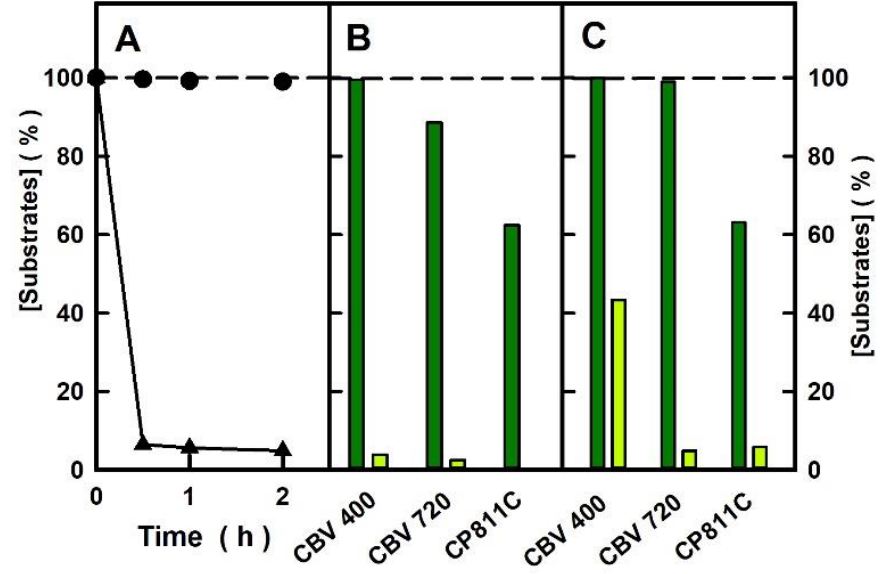

Figure 3. (A) Time-course profile of both the solketal ( $\mathbf{A})$ and ethyl decanoate (O) concentration in a water/t-butanol medium with the presence of CBV720 acid zeolite at $50{ }^{\circ} \mathrm{C}$. Ethyl decanoate (dark) and solketal (clear) concentration in a water/t-butanol medium after $2 \mathrm{~h}$ in the presence of an acid zeolite (i.e. CBV400, CBV720 or CP811-C) at $80^{\circ} \mathrm{C}(\mathrm{B})$, or $50{ }^{\circ} \mathrm{C}(\mathrm{C})$

full conversion of TAGs in FASEs, which was only observed when the solketal concentration was at least 3.5-times higher than that for TAGs concentration (see Table 1,entries 3 and 4). The obtained product yield for a 1:2 (mol:mol) omega-3 oil:solketal ratio (see entry 1) could also be considered as a good result, because the final reaction media just contained a mixture of FASEs and MAGs.

However, taking into account the differences in hydrophilicity between both the FASE and the MAG products, a 1:3.5 (mol:mol) TAGs:solketal ratio was selected as the optimal ratio for further biocatalytic procedures, because of the favoured mass-transport processes of the hydrophobic FASEs, with respect to MAGs, by the $\mathrm{scCO}_{2}$ flow. ${ }^{19 \mathrm{~d}}$ In the same context, the extraction of hydrophobic compounds from SLILs by using the sponge-like technology involves the use of water for separation of all the hydrophilic compounds into a middle aqueous phase, remaining the pure hydrophobic compounds in the top phase. ${ }^{23}$ By a full transformation of TAGs in FASEs, the separation of pure products is clearly improved. ${ }^{22 d, 25}$

\section{Acid zeolites-catalysed hydrolysis of the solketal ring.}

The opening of the solketal ring to produce the corresponding glycol can be carried out by a controlled acid-catalytic hydrolysis. ${ }^{26}$ For the case of FASEs, it is necessary to take into account that a proper selection of the acidic strength of the catalyst is key to provide the desired omega-3 MAGs products by a selective hydrolysis of the ketal ring moiety, without affecting the ester linkage (see Fig. 1). In this context, the suitability of three different acid zeolites (CBV400, CBV720 and CP811-C) for catalysing the hydrolysis of solketal and ethyl decanoate, as a model ester, was tested in water/t-butanol reaction medium at 50 and $80{ }^{\circ} \mathrm{C}$, respectively. Figure $3 \mathrm{~A}$ depicts the time-course profile of ethyl decanoate and solketal concentrations in the presence of the zeolite CBV 720 at $50{ }^{\circ} \mathrm{C}$. The concentration of the ester compound remained constant for $2 \mathrm{~h}$ of reaction, while the ketal concentration was rapidly decreased. Figure 3B shows the remaining solketal and ethyl decanoate concentrations in the reaction media after $2 \mathrm{~h}$ reaction for each of the zeolite tested at 80 ${ }^{\circ} \mathrm{C}$. As can be seen, all zeolites were able to fully hydrolyse the offered solketal after $2 \mathrm{~h}$ (remaining concentration $<5 \%$ ), while some decrease in the concentration of the ester was also observed when increasing the acidic strength of the zeolite (CBV400 < CBV720 < CP811-C), according to their Si/Al ratio (see Experimental Section). Both CBV720 and CP811-C zeolites could be considered as unappropriated to carry out the production of MAGs from FASES at $80^{\circ} \mathrm{C}$, because of the undesired hydrolysis of the ester linkage that occurs simultaneously with solketal hydrolysis. Alternatively, when the same reaction systems were assayed at $50{ }^{\circ} \mathrm{C}$ (see Fig. $3 \mathrm{C}$ ), only the middle acidic zeolite (CBV720) was able to provide full solketal hydrolysis maintaining unchanged the ethyl decanoate concentration. Although this result was similar to the obtained by the lowest acidic zeolite (CBV400) at 80 o C (Fig. 3B), the use of CBV720 zeolite at $50{ }^{\circ} \mathrm{C}$ was selected as the catalytic system for further studies, because of the better suitability of low temperatures for the industrial processing of omega-3 oils. ${ }^{27}$ Other strong acidic catalysts based on sulfonic groups (e.g. Amberlyst-15) led to worse results, because of the full hydrolysis of ketal and ester, even at room temperature (data not shown).

Continuous chemocatalytic synthesis of omega-3 MAGs in $\mathrm{scCO}_{2}$ flow

The excellent suitability of biphasic systems, based on a combination of ILs and $\mathrm{scCO}_{2}$ with enzymes, has been reported as an important "arsenal" of green tools to develop clean chemical processes of industrial interest, ${ }^{16,19,28}$ even with multi-catalytic steps. ${ }^{29}$ In this context, a two reactors system connected in series was developed to carry out the synthesis of omega-3 MAGs from omega-3 TAGs and solketal in $\mathrm{scCO}_{2}$ (see Fig. 4). As can be seen, the first reactor contained the Novozym 435 particles coated with [ $\left.\mathrm{C}_{18} \mathrm{tma}\right]\left[\mathrm{NTf} \mathrm{f}_{2}\right]$, because of the protective effect of this IL against the denaturation effect of $\mathrm{scCO}_{2} .{ }^{18 b, 28,29}$ The second reactor was based in a catalytic packed bed system, containing the CBV720 acid zeolite. The system operated with a continuous feed of both the omega- 3 oil and solketal substrates at the entry of the first reactor, being directly transported by the $\mathrm{scCO}_{2}$ phase to the biocatalyst-IL microenvironment. The resulting FASEs products were subsequently transported by the supercritical fluid to the exit of this biocatalytic module. Then, the FASEs-scCO flow was continuously mixed with a water/t-butanol mixture by a pump, being fed to the second reactor containing the acid zeolite catalysts to carry out the selective hydrolysis of the solketal moiety of FASEs, and to produce the final omega-3 MAGs under continuous operation.

For this supercritical bi-catalytic flow system, it is necessary to underline that the hydrophobic character of $\mathrm{scCO}_{2}$ does not permit the extraction or the transport of hydrophilic compounds, like glycerol or water, being necessary the presence of an hydrophilic cosolvent like ethanol or $t$-butanol for improving this operation. ${ }^{30}$ In this context, it should be pointed out that the feeding of the second reactor with pure water led to its direct adsorption on the zeolite, resulting in an inactive wet catalyst and the clogging of the system after several hours of operation. In order avoid this drawback and to maintain the necessary mass-transport of FASEs to the zeolite, and the return of the synthesized MAGs to the $\mathrm{scCO}_{2}$ flow, water was introduced as a mixture at $50 \%(\mathrm{v} / \mathrm{v})$ in $t$-butanol, as a solvent suitable to dissolve acylglycerides. ${ }^{19 d, 31}$ 


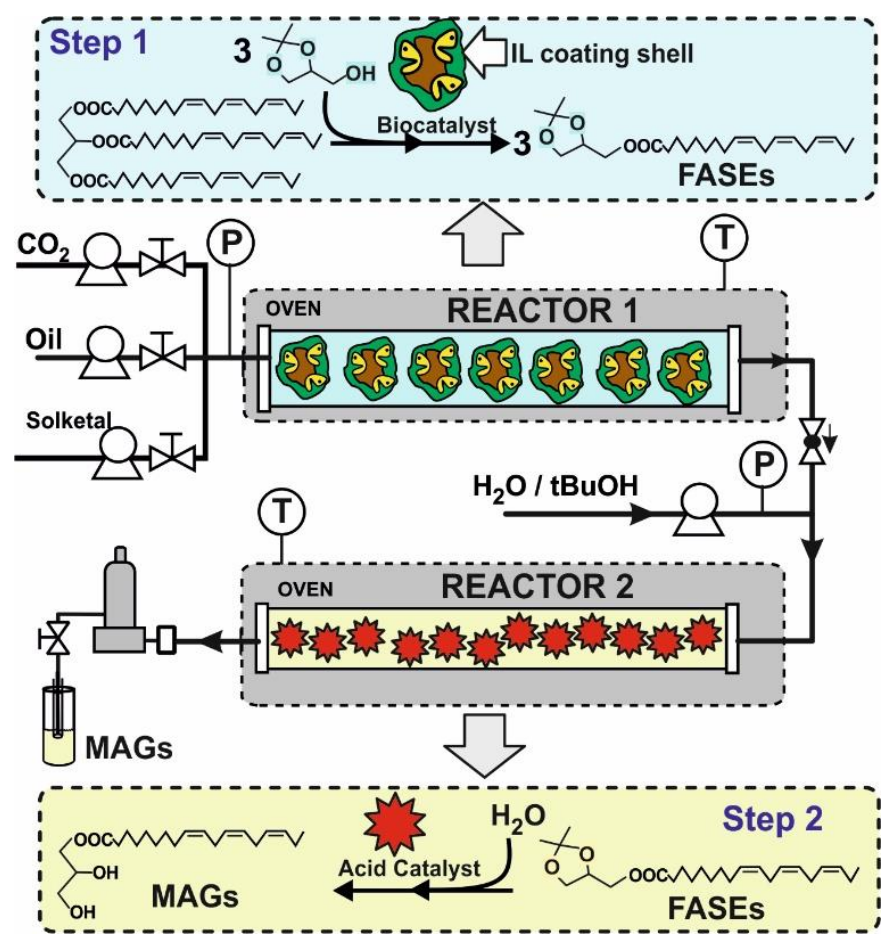

Figure 4. Experimental set-up for the continuous $\mathrm{scCO}_{2}$ bi-reactor system system, containing Novozym 435 coated with [ $\mathrm{C}_{18}$ tma][NTf $\mathrm{N}_{2}$ (Reactor 1 ), and the CBV720 acid zeolite (Reactor 2), for the transformation in two-steps of TAGs to omega-3 MAGs. See experimental section for further details.

Figure 5 A shows the time course profile of the omega-3 MAG yield obtained by the bi-reactor system when using fish oil as substrate. As can be seen, the system reached a $100 \%$ yield after $2 \mathrm{~h}$ operation. This was maintained for a short time before a continuous decay was observed up ca. $45 \%$ yield, which could be related to the deactivation of the biocatalyst. ${ }^{16 a}$ However, washing the Novozym

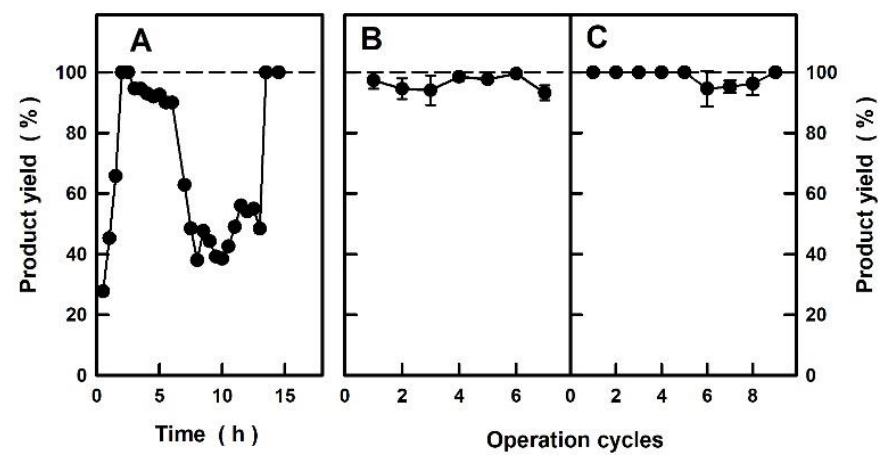

Figure 5. A. Time-course profile of the continuous omega-3 MAGs synthesis catalysed by two consecutive reactors, containing Novozym-435 coated with [ $\mathrm{C}_{18}$ tma] [NTf 2 , and the $\mathrm{CBV720}$ acid zeolite, respectively, under a $\mathrm{SCCO}_{2}$ flow $(1.5 \mathrm{~mL} / \mathrm{min}, 18 \mathrm{MPa})$ at $60^{\circ} \mathrm{C}$. The biocatalytic reactor was fed with fish oil (0.076 $\mu \mathrm{L} / \mathrm{min} ; 8 \mu \mathrm{mol} / \mathrm{min}$ ) and solketal (36 $\mu \mathrm{L} / \mathrm{min} ; 28.8 \mu \mathrm{mol} / \mathrm{min}$ ). Operational stability of the proposed Novozym 435-IL/CBV720 zeolite bireactor system at the conditions reported above, being fed by fish (B) or linseed (C) oils, respectively, containing $10 \%(\mathrm{v} / \mathrm{v}) t$-butanol. Each point corresponds to the average value of all samples obtained during each $6 \mathrm{~h}$ cycle. See experimental section for further details
$435 /\left[\mathrm{C}_{18} \mathrm{tma}\right]\left[\mathrm{NTf}_{2}\right]$ catalytic system with $t$-butanol after $14 \mathrm{~h}$ operation and re-coating again the biocatalyst with the IL, led to the full recovery of the catalytic activity, resulting again a $100 \%$ omega3 MAGs yield. As previously reported, ${ }^{19 d}$ this activity decay could be attributed to the low efficiency of the hydrophobic $\mathrm{scCO}_{2}$ phase to transport the hydrophilic by-product glycerol out of the biocatalysts particles, being retained in the IL layer coating the support. This fact leads to a continuous biocatalyst poisoning, hindering the entry of fresh TAGs to the biocatalyst active sites.

In this context, the suitability of this supercritical bi-catalytic flow system was improved under continuous conditions by adding $10 \%$ $(\mathrm{v} / \mathrm{v}) t$-butanol into the fish (Fig. 5B) and linseed (Fig. 5C) oils used as substrate. As can be seen, the catalytic activity shown by the enzyme was practically unchanged for all the assayed operation cycles, whith the omega-3 MAGs yield being over $95 \%$ in all cycles. It is worth mentioning that the presence of $t$-butanol reduced the viscosity of the oil substrate, facilitating the work of the HPLC pump. These results point out the importance of mass-transfer limitations for continuous multi-reactor systems under $\mathrm{scCO}_{2}$ to achieve long-term productivities when processing triglycerides. ${ }^{18}$

The excellent suitability of the proposed supercritical bi-catalytic system is tarnished by the presence of the glycerol by-product and the $t$-butanol co-solvent in the omega-3 MAGs flow, being necessary a further separation step to obtain pure product (e.g. molecular distillation). ${ }^{32}$ Although ILs are non-miscible with $\mathrm{scCO}_{2}$, it should be noted that a residual IL content $\left(<0.2 \%\right.$, as determined by $\left.{ }^{19} \mathrm{~F} \mathrm{NMR}\right)$ was also present, because of the ability of both solketal and $t$-butanol to dissolve a minor amount of the IL adsorbed onto the immobilized enzyme particles under operational conditions. In this context, the use of immobilized lipases onto supported ionic liquid-like phases (SILLPS), based on the covalently binding IL-like fragments on the surface of the solid supports, has been reported as a useful alternative to avoid the loss of the IL-coating enzyme under the operation flow. ${ }^{16 b, 19}$

\section{Chemocatalytic synthesis of omega-3 MAGs in liquid medium.}

In an attempt to directly obtain a pure omega-3 MAG product through the above reported catalytic step, avoiding the use of cosolvents like $t$-butanol, an alternative discontinuous experimental set-up was developed. This approach was based on the excellent suitability of the sponge-like ionic liquids technology to carry out both the biocatalytic transformations of hydrophobic substrates, and the subsequent separation between the pure products and the IL by a straightforward protocol, affording the reuse of all the elements of the reaction system (i.e. catalysts and $\mathrm{IL}$ ). ${ }^{23}$ In this context, the assayed experimental set-up for the production of nearly pure omega-3 MAGs from omega-3 TAGs by using the SLIL technology was based in three main steps (see Fig. 6).

The first step concerns the Novozym 435-catalysed transesterification of TAGs with solketal to produce FASEs using the $\left[\mathrm{C}_{18} \mathrm{tma}\right]\left[\mathrm{NTf}_{2}\right] \mathrm{IL}$ as reaction medium at $60^{\circ} \mathrm{C}$. After $6 \mathrm{~h}$ of reaction, the immobilized enzyme particles were separated by simple centrifugation, then washed with $t$-butanol to eliminate glycerol hydrophilic shell that poisons the biocatalyst, ${ }^{22 b}$ and finally stored for $12 \mathrm{~h}$ in a desiccator for further reuse. Figure 7 shows the residual activity of these recovered immobilized enzymes in the synthesis of 


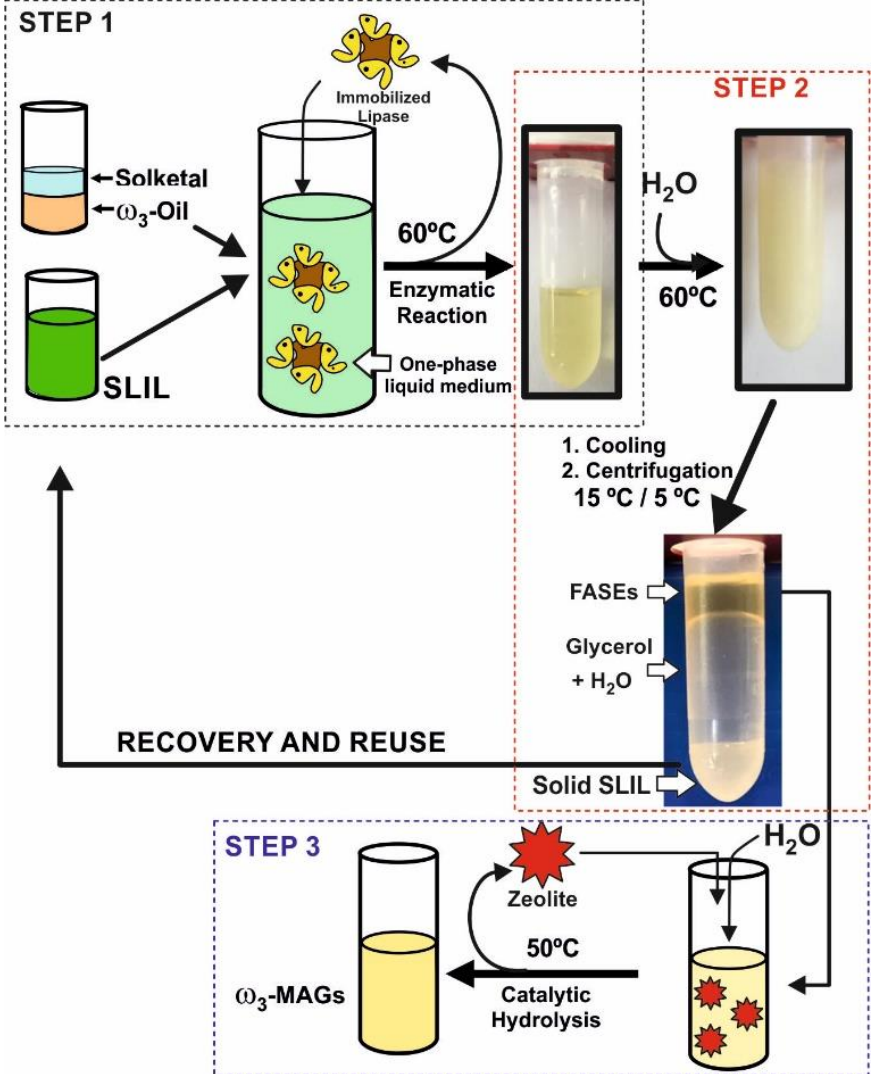

Figure 6. Scheme of the cyclic protocol for the production of omega-3 MAGs in three steps. Step 1. Novozym-435-catalysed FASEs synthesis by transesterification of omega-3 oils with solketal in $40 \%(\mathrm{w} / \mathrm{w})$ [ $\mathrm{C}_{18} \mathrm{tma}^{\mathrm{t}}$ ] $\left.\mathrm{NTf}_{2}\right]$ at $60{ }^{\circ} \mathrm{C}$. Step 2. Separation of FASEs/[C $\left.\mathrm{C}_{18} \mathrm{tma}\right]\left[\mathrm{NTf}_{2}\right]$ reaction mixtures by adding hot water $\left(60^{\circ} \mathrm{C}\right)$, shaking and centrifuging twice $(15000 \mathrm{rpm}, 15$ minutes, $15{ }^{\circ} \mathrm{C}$; $\left.15000 \mathrm{rpm}, 15 \mathrm{~min}, 5{ }^{\circ} \mathrm{C}\right)$. Step 3. CBV720 acid zeolitecatalysed omega-3 MAGs synthesis by hydrolysis of omega-3 FASEs with water ( $24 \% \mathrm{v} / \mathrm{v}$ final concentration) at $50{ }^{\circ} \mathrm{C}$. Experimental Section for further details.

omega-3 FASEs by the transesterification of fish and linseed oils with solketal for seven consecutive catalytic cycles of enzyme reuse. As can be seen, the enzyme showed a constant level in activity, with just a slight decrease for the last two cycles, probably due to the uncontrolled loss in enzyme particles during the washing steps. Once again, the excellent suitability of a hydrophobic ionic liquid, based on cations with large ILs, based on large alkyl chains in the cation and the $\left[\mathrm{NTf}_{2}\right]$ anion, provided an excellent microenvironment for the catalytic activity of lipase B from Candida antarctica. ${ }^{22,23}$

The second step consisted in the fractionated separation of the components of the reaction media: FASEs, SLIL, glycerol by-product and residual solketal. As shown in Fig. 6, the addition of hot water into the fully clear and monophasic reaction medium obtained from the biocatalytic step, led to a heterogeneous mixture, because of the precipitation of the solid SLIL, which improved upon cooling to room temperature. The semisolid heterogeneous mixture obtained was then separated by following an iterative cooling / centrifugation protocol (15000 rpm, 15 minutes, $15{ }^{\circ} \mathrm{C} ; 15000 \mathrm{rpm}, 15 \mathrm{~min}, 5^{\circ} \mathrm{C}$ ), resulting in three phases: an upper IL-free omega-3 FASEs phase, a middle IL-free liquid aqueous phase containing glycerol and the excess of solketal, and a bottom solid containing the SLIL. The

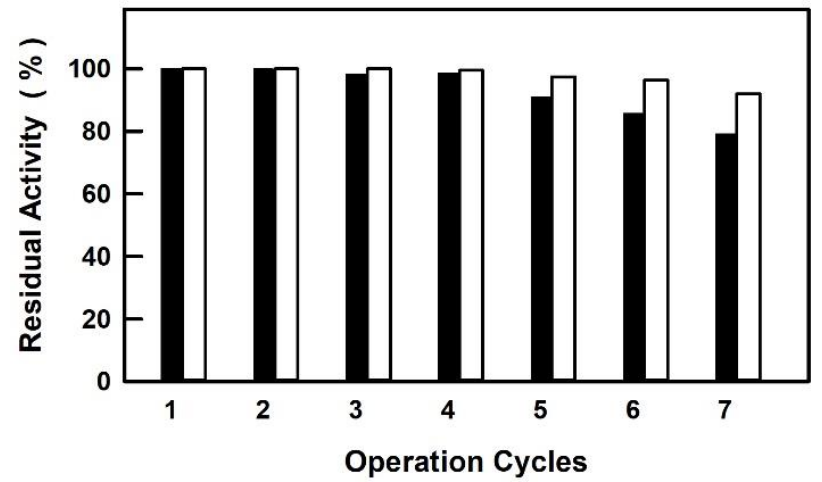

Figure 7. Operational stability of the Novozyme $435 /\left[\mathrm{C}_{18} \mathrm{tma}\right.$ ] $\left.\mathrm{NTf}_{2}\right]$ (40\% $\mathrm{w} / \mathrm{w}$ ) system for producing FASEs by the transesterification of linseed (white) or fish (black) oils with solketal for $6 \mathrm{~h}$ of reaction at $60^{\circ} \mathrm{C}$

washing with water, as a green molecular solvent immiscible with the omega-3 FASEs and the SLIL, favoured the clean separation of all the components, ${ }^{18,25}$ providing an easy and sustainable way to separate nearly pure FASEs, that could be collected and directly used for the final catalytic step. The solid IL was recovered, dried, and stored into a desiccator for further reuse.

Additional features to be considered regarding the suitability of SLILS for this proposed separation approach concern the excellent stability (e.g. thermal, ${ }^{33}$ electrochemical, ${ }^{34}$ and even against gamma irradiation, ${ }^{35}$ etc.) of ILs based on the $\left[\mathrm{NTf}_{2}\right]$ anion, being not affected by the presence of water. ${ }^{36}$ Indeed, the insolubility in water of the SLILs, as well as the melting points higher than room temperature displayed by these ILs, allow their immediate precipitation as solids and their easy full recovery, even after a possible accident during handling. ${ }^{23}$ Outside a possible optimization of the washing-by-water step (e.g. water volume, type of mixing, etc.), these features also involve that the middle aqueous phase may be considered as being an IL-free glycerol solution in water that could be recovered, rather than being defined as wastewater.

As depicted in Fig. 6, the third step consisted in the hydrolysis of the ketal ring in omega-3 FASEs catalysed by the CBV720 acid zeolite at $50{ }^{\circ} \mathrm{C}$. Taking into account the limited solubility of water in FASEs, as well as the hygroscopic character of zeolites, a 1:7.5 (mol:mol) FASEs:water ratio was assayed. This ratio provided enough water molecules for the catalytic reaction, and still afforded a fully clear and monophasic reaction medium prior to the addition of the zeolite. Figure 8 shows how the omega-3 MAGs yield resulting from this catalytic reaction was close to $100 \%$ for the linseed FASEs and remained unchanged for six operational cycles of reuse of the zeolite. The decay in the product yield observed for the last operation cycles could be due to the uncontrolled loss in zeolite particles during the washing steps (see Experimental section). This behaviour was also observed for the case of FASEs obtained from fish oil, although the maximum omega-3 MAGs yield observed was limited to $c a$. $70 \%$. It should be noted that the fish oil used as the initial substrate is a raw material from a natural source, containing unknown compounds other than TAGs that could be adsorbed onto the zeolite reducing the hydrolytic activity. Indeed, a continuous browning of the zeolite with reuse during operational cycles was observed, even after 


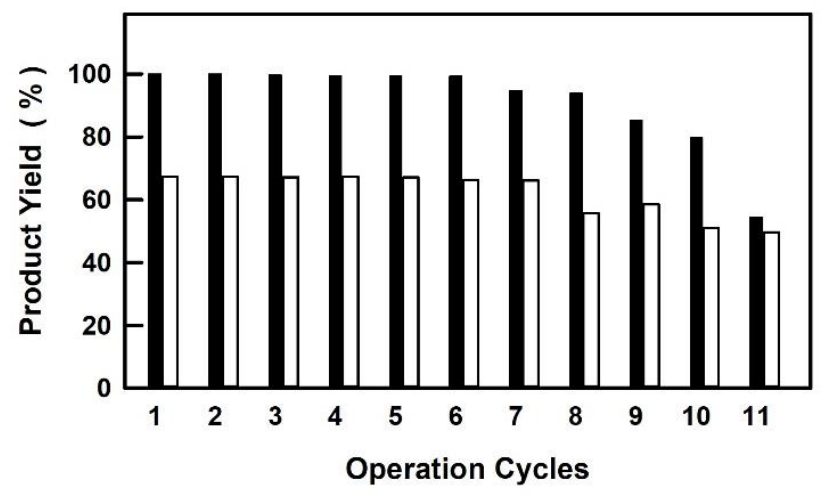

Figure 8. Operational activity of the CBV720 acid zeolite as catalyst for the synthesis of omega-3 MAGs by hydrolysis of the FASEs, obtained from linseed (black) and fish (white) oils (1:7.5 water:FASEs molar ratio) at $50{ }^{\circ} \mathrm{C}$.

washing, while no changes in colour was detected in the case of linseed oil.

To assess the practical suitability of the (chemo)enzymatic process for producing omega-3 MAGs from fish or linseed raw edible oils, its scale up, by a factor of 20 , was carried out by using $50-\mathrm{mL}$ Falcon tubes. As can be seen in Fig. 9, the fully clear reaction media obtained after the biocatalytic reaction (Step 1 ) became cloudy after addition of a similar volume of hot water $(60 \stackrel{\circ}{\circ})$ and shaking at room temperature. This step was key for the extraction of both the glycerol by-product and the excess of solketal, as hydrophilic molecules, to the aqueous phase, (Fig. 9B). By following the corresponding cooling and centrifugation protocol (Step 2), the efficient separation between all components of the system (i.e. the solid SLIL at the bottom, the glycerol and solketal at the middle aqueous phase, and the pure omega-3 FASEs at the top phase) was easily carried out (Fig. 9C).

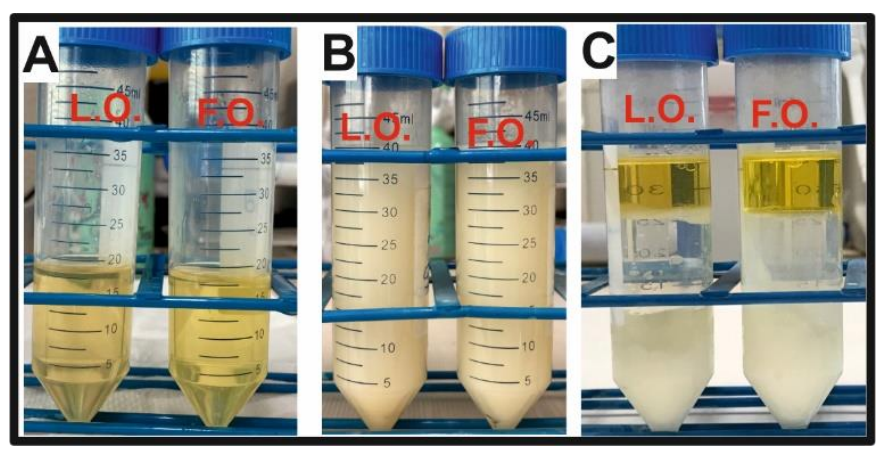

Figure 9. A. Reaction media obtained after the biocatalytic synthesis of omega-3 FASEs from linseed (L.O.) and fish (F.O.) oils in [ $\left.\mathrm{C}_{18} \mathrm{tma}_{\mathrm{tm}}\right]\left[\mathrm{NTf}_{2}\right]$. B. Heterogenous mixtures resulting by the addition of hot water into the reaction media. C. Separation between both the omega-3 FASEs (upper phase) and the $\left[\mathrm{C}_{18}\right.$ tma] $\left[\mathrm{NTf}_{2}\right]$ IL (bottom phase) by following the cooling/centrifugation protocol. (see Experimental Section for further details).

The synthetic product yields of this biocatalytic step were ca. 99 $\%$ for both oils. After the careful collection of the FASEs product, the acid hydrolysis of the solketyl moieties was carried out by the zeolite catalyst in separate tubes (Step 3), resulting in fully clear reaction media containing the nearly pure omega-3 MAGs (98\% and $70 \%$ $\mathrm{w} / \mathrm{w}$ yields for the linseed and fish oil, respectively). The suitability of the proposed protocol can be attributed not only on the high yield of nearly pure omega-3 MAG products, but also on the excellent recovery yield of the solid SLIL (ca. $99 \% \mathrm{w} / \mathrm{w}$ ), pushing directly to its straightforward implementation over any scaling up process.

\section{Conclusions}

The chemo-enzymatic approach for the synthesis of omega-3 MAGs from raw fish and linseed oils was successfully carried out in IL and $\mathrm{IL} / \mathrm{scCO}_{2}$ reaction media. The strategy was based in two consecutive catalytic steps, involving the selective transformation of TAGs in FASEs by Novozym 435, followed by the hydrolysis of the ketal moieties of FASEs carried out by an acid zeolite. The SLIL $\left[\mathrm{C}_{18} \mathrm{tma}\right]\left[\mathrm{NTf} \mathrm{f}_{2}\right]$ was shown to be an excellent reaction medium for the lipase-catalysed transesterification reaction of omega-3 TAGs with solketal, even in continuous operation under supercritical conditions. In the same way, the appropriate selection of the acid catalyst and the reaction temperature has been shown as key parameters to achieve the selective hydrolysis of the ketal moiety without affecting the ester linkage inside the MAGs molecules.

Although both the continuous and the discontinuous approaches provided excellent results for omega-3 MAGs production, the need for the use of $t$-butanol, as a polar co-solvent enabling the masstransport phenomena of hydrophilic compounds, tarnish the continuous approach under supercritical conditions. The discontinuous strategy based on the SLIL technology permitted the selective transformation and separation of the intermediate FASEs product, with full recovery of the IL for further reuse. Thus, the extracted omega-3 FASEs may selectively be transformed to omega3 MAGs by an acid zeolite-catalysed hydrolytic reaction under mild conditions. Using this approach, almost pure omega-3 MAG products were obtained, while the recovery and reuse of the elements of the catalytic system (biocatalyst and acid catalyst), led to maintenance in activity for many operation cycles.

These results clearly represent a sustainable approach to produce omega-3 MAGs by using raw sources of omega-3 TAGs, pushing on the development of green chemical multi-catalytic processes at an industrial level.

\section{Conflicts of interest}

There are no conflicts to declare.

\section{Acknowledgements}

This work was partially supported by RTI2018-098233-B-C21 and RTI2018-098233-B-C22 (MICINN), PROMETEO/2016/071 (Generalitat Valenciana) and 20790/PI/18 (Fundacion SENECA CARM) grants.

\section{Notes and references}


1 a) C. Cruz-Hernandez, F. Destaillats, S. K. Thakkar, L. Goulet, E. Wynn, D. Grathwohl, C. Roessle, S. de Giorgi, L. Tappy, F. Giuffrida and V. Giusti, J. Lipid Res. 2016, 57, 2208-2216; b) P. Perez-Martinez, N. Katsiki and D. P. Mikhailidis, Angiology 2020, 71, 10-16.

2 a) R. Siener, B. Alteheld, B. Terjung, B. Junghans, N. Bitterlich, P. Stehle and C. Metzner, Eur. J. Clin. Nutr. 2010, 64, 410-418; b) M. Cholewski, M. Tomczykowa, M. Tomczyk, Nutrients, 2018, 10, Art N. 1662. DOI: 10.3390/nu10111662; c) R. Lopez-Fandino, Crit. Rev. Food Sci. Nutr. 2020, 60, 1797-1814.

3 a) A. Valenzuela, V. Valenzuela, J. Sanhueza and S. Nieto, Ann. Nutr. Metab. 2005, 49, 49-53; b) C. Cruz-Hernandez, S. K. Thakkar, J. Moulin, M. Oliveira, I. Masserey-Elmelegy, F. Dionisi and F. Destaillats, Nutrients, 2012, 4, 1781-1793.

4 a) A. G. Solaesa, M. T. Sanz, R. Melgosa and S. Beltran, Food Res. Int. 2017, 100, 572-578; b) A. G. Solaesa, M. T. Sanz, R. Melgosa and S. Beltran, LWT-Food Sci. Technol. 2018, 96, 228-235; c) H. J. Chang and J. H. Lee, J. Sci. Food Agric. 2020, 100, 287-294

5 a) N. J. Zhong, L. Z. Cheong and X. B. Xu, Eur. J. Lipid Sci. Technol. 2014, 116, 97-107; b) H. Zhang, Y. A. Cui, S. M. Zhu, F. Q. Feng and X. D. Zheng. Int J. Pharm. 2010, 395, 154-160; c) D. Vollhardt and G. Brezesinski, J. Phys. Chem. C, 2015, 119, 9934-9946.

6 J. Pérez-Pariente, I. Diaz, F. Mohino and E. Sastre, Appl. Catal. A Gen. 2003, 254, 173-188. b) I. Díaz, C. Marquez-Alvarez, F. Mohino, J. Perez-Pariente and E. Sastre, J. Catal. 2000, 193, 295302.

7 European Food Emulsifier Manufactures Association, e.V. E 471, in EFEMA Index of Food Emulsifiers, June 2015 Ed., pp. 51-56 (see http://www.emulsifiers.org).

8 a) M. L. Damstrup, T. Jensen, F. V. Sparso, S. Z. Kiil, A. D. Jensen and X. Xu, J. Am. Oil Chem. Soc. 2006, 83, 27-33; b) B. Perez, B. S. Hansen, P. A. Bulsara, A. V. Rawlings, M. J. Clarke and Z. Guo, Int. J. Cosmetic Sci. 2017, 39, 511-517.

9 M. M. C. Feltes, D. de Oliveira, J. M. Block and J. L. Ninow, Food Bioprocess Tech. 2013, 6, 17-35; b) A. G. Solaesa, M. T. Sanz, M. Falkeborg, S. Beltran and Z. Guo, Food Chem, 2016, 190, 960-967; c) D. Palacios, N. Ortega, N. Rubio-Rodriguez and M. D. Busto, Food Chem. 2019, 271, 372-379; d) L. Koop, L. I. Soares, F. A. P. Voll, A. Bonilla-Petriciole and M. L. Corazza, Chem. Eng. Commun. 2020, 207, 93-108.

10 a) R. Pawongrat, X. B. Xu and A. H-Kittikun, J. Sci Food Agric. 2008 88, 256-262; b) E. Subroto, Supriyanto, T. Utami, Food SC Biotechnol. 2019, 28, 511-517.

$11 \mathrm{~S}$. Baum, E. Ritter, I. Smirnova, M. Schilling and A. Liese, RSC Adv. 2016, 6, 32422-32429.

12 E. Castillo, V. Dossat, A. Marty, J. S. Condoret and D. Combes, J. Am. Oil Chem. Soc. 1997, 74, 77-85.

13 a) H. Keskin, D. K. Yanik, H. N. Mucuk, F. Gogus, S. Fadiloglu, J. Food Sci. 2016, 81, 841-848; b) N. Castejon and F. J. Senorans, Eur. J. Lipid Sci. Technol. 2019, 121, Art. № 1800412. DOI: 10.1002/ejlt.201800412; c) Y. Zhang, X.S. Wang, D. Xie, S. Zou, Q.Z. Jin and X.G. Wang, Food Chem. 2019, 250, 60-66.

14 R. Melgosa, M.T. Sanz, O. Benito-Roman, A. E. Illera and S. Beltran, J. CO2 Util. 2019, 31, 65-74.

15 a) J. Dupont, R. F. de Souza and P. A. Z. Suarez, Chem. Rev., 2002, 102, 3667-3699; b) P. D. de Maria, Angew. Chem, Int. Ed. 2008, 47, 6960-6968; c) J. Dupont. Acc. Chem, Res. 2011, 44, 12231231; d) I. Bodachivskyi, U. Kuzhiumparambil and D. B. G. Williams, ChemSusChem, 2018, 11, 642-660. d) G. Chacon and J. Dupont, Chem CatChem, 2019, 11, 333-341.

16 a) P. Lozano, Green Chem. 2010, 12, 555-569; b) P. Lozano, J. M. Bernal S. Nieto, C. Gomez, E. Garcia-Verdugo and S. V. Luis, Chem. Commun. 2015, 51, 17361-17374; c) T. Itoh, Chem. Rev. 2017, 117, 10567-10607.

17 a) D. R. MacFarlane, M. Kar and J. M. Pringle, Fundamentals of Ionic Liquids: From Chemistry to Applications, Wiley- VCH, Verlag, Weinheim, 2017; b) F. P. Kinik, A. Uzun and S. Keskin. ChemSusChem, 2017, 10, 2842-2863; c) P. Lozano, Sustainable Catalysis in Ionic Liquids, CRC Press, New York, 2018

18 a) E. Garcia-Verdugo, B. Altava, M. I. Burguete, P. Lozano and S. V. Luis. Green Chem. 2015, 17, 2693-2713; b) N. Guajardo and P. D. de Maria, ChemCatChem, 2019, 11, 3128-3137; c) R. Villa, E. Alvarez, R. Porcar, E. Garcia-Verdugo, S. V. Luis and P. Lozano, Green Chem. 2019, 21, 6527-6544.

19 a) P. Lozano, T. De Diego, D. Carrie, M. Vaultier, J. L. Iborra, Chem. Commun. 2002, 692-693; b) P. Lozano, E. Garcia-Verdugo, R. Piamtongkam, N. Karbass, T. De Diego, M.I. Burguete, S. V. Luis and J. L. Iborra, Adv. Synth. Catal. 2007, 349, 1077-1084; c) P. Lozano, T. De Diego, C. Mira, K. Montague, M. Vaultier and J. L. Iborra, Green Chem. 2009, 11, 538-542; d) P. Lozano, E. GarciaVerdugo, J. M. Bernal, D. I. Izquierdo, M. I. Burguete, G. SanchezGomez and S. V. Luis, ChemSusChem, 2012, 5, 790-798.

20. Luo, Z. Zhai, W. Y. Fan, W. Y. Cui, G. Z. Nan and Z. M. Li. Ind. Eng. Chem. Res. 2015, 54, 4923-4928.

21 Z. Guo, X. B. Xu. Org. Biomol. Chem. 2005, 3, 2615-2619; b) Z. Guo and X. B. Xu. Green Chem, 2006, 8, 54-62; c) Z. Guo, B. Q. Chen, R. L. Murillo, T. W. Tan and X. B. Xu, Org. Biomol. Chem. 2006, 4, 2772-2776.

22 a) P. Lozano, J. M. Bernal, R. Piamtongkam, D. Fetzer and M Vaultier, ChemSusChem, 2010, 3, 1359-1363; b) P. Lozano, J. M. Bernal, G. Sanchez-Gomez, G. Lopez-Lopez and M. Vaultier. Energy Environ. Sci, 2013, 6, 1328-1338; c) P. Lozano, J. M. Bernal and A. Navarro, Green Chem. 2012, 14, 3026-3033; d) E. Alvarez, J. Rodriguez, R. Villa, C. Gomez, S. Nieto, A. Donaire and P. Lozano. ACS Sustain. Chem. Eng. 2019, 7, 13307-13314.

23 P. Lozano, J. M. Bernal, E. Garcia-Verdugo, G. Sanchez-Gomez, M. Vaultier, M. I. Burguete and S. V. Luis. Green Chem. 2015, 17, 3706-3717.

24 P. Lozano, C. Gomez, S. Nieto, G. Sanchez-Gomez, E. GarciaVerdugo and S. V. Luis. Green Chem. 2017, 19, 390-396. 
31 D. Royon, M. Daz, G. Ellenrieder and S. Locatelli, Bioresour. Technol. 2006, 98, 648-653.

32 J.L. He, B.H. Hong, R. Lu, R.Q. Zhang, H. Fang, W. W. Huang, K.K. Bai and J.P. Sun, Food Sci Nutr. 2020, 8, 2234-2241.

33 P. Bonhote, A. P. Dias, N. Papageorgiou, K. Kalyanasundaram and M. Gratzel, Inorg. Chem., 1996, 35, 1168-1178.

34 F. Philippi, D. Pugh, D. Rauber, T. Welton and P. A. Hunt. Chem. Sci. 2020, 11, 6405-6422.

35 L. Berthon, S. I. Nikitenko, I. Bisel, C. Berthon, M. Faucon, B. Saucerotte, N. Zorz and P. Moisy. Dalton Trans., 2006, 25262534.

25 P. Lozano, C. Gomez, A. Nicolas, R. Polo, S. Nieto, J. M. Bernal, E. Garcia-Verdugo and S. V. Luis. ACS Sustain. Chem. Eng. 2016, 4, 6125-6132.

26 L. P. Ozorio, R. Pianzolli, M. B. S. Mota and C. J. A. Mota. J. Braz. Chem. Soc. 2012, 23, 931-937.

27 C. Turek and F. C. Stintzing, Compr. Rev. Food Sci. Food Saf. 2013 12, 40-53.

28 P. Lozano, J. M. Bernal and M. Vaultier, Fuel 2011, 90, 3461-3467, b) P. Lozano, E. Garcia-Verdugo, S. V. Luis, M. Pucheault and M. Vaultier, Curr. Org. Synth. 2011, 8, 810-823.

29 P. Lozano, T. De Diego, C. Mira, K. Montague, M. Vaultier and J.L. Iborra, Green Chem. 2009, 11, 538-542.

30 O. Guclu-Ustundag and F. Temelli, J Supercrit. Fluids, 2005, 36, 115.

36 S. Steudte, J. Neumann, U. Bottin-Weber, M. Diedenhofen, J. Arning, P. Stepnowskia and S. Stolte, Green Chem., 2012, 14, 2474-2483. 